\title{
Los tipos sancionatorios en blanco en el proceso disciplinario. Un análisis desde el debido proceso*
}

\author{
Jonathan Zapata Flórez"* \\ Recibido: 11 de diciembre de 2015 - Aprobado: 30 de abril de 2017 \\ DOI: 10.22395/ojum.v16n3la8
}

\section{RESUMEN}

El derecho disciplinario se compone de un conjunto de normas jurídicas sustantivas y procedimentales que tienen como finalidad determinar ciertos actos objeto de reproche, previendo las sanciones que se pueden imponer a un conjunto de personas a través de un procedimiento especializado. Como derecho sancionador se compone de tipos que determinan los hechos y la sanción respectiva, con la peculiaridad que en asuntos disciplinarios estos poseen una estructura flexible. Este artículo plantea y concluye que los tipos en blanco pueden resultar atentatorios del debido proceso. El escrito comienza dando cuenta de la naturaleza del derecho disciplinario, luego aborda el tema del tipo en blanco para pasar a relacionarlo con el conflicto que su aplicación suscita de cara al derecho fundamental al debido proceso.

Palabras clave: Derecho disciplinario; derecho fundamental al debido proceso; principio de legalidad; tipo en blanco.

Este trabajo es producto del proceso de investigación desarrollado en la Universidad de Antioquia, Facultad de Derecho y Ciencias Políticas, en el año 2015.

* Abogado, Universidad de Antioquia. Politólogo, Universidad Nacional de Colombia. Especialista en Derecho Procesal, Universidad de Antioquia. Especialista en Derecho Comercial, Universidad Autónoma Latinoamericana. Maestrando en Derecho, Universidad Pontificia Bolivariana. Docente ocasional de tiempo completo de la Facultad de Derecho y Ciencias Políticas de la Universidad de Antioquia. Correo: jonathan.zapataf@ udea.edu.co. 


\title{
Types of Incomplete Norms in a Disciplinary Process. An analysis from the Point of View of the Due Process
}

\begin{abstract}
Disciplinary law consists of a set of substantive and procedural juridical norms intended to set certain reproachable actions foreseeing the penalties that can be imposed to a number of people through a special procedure. As punitive law, it consists of types which set facts and relevant penalty; however, they hold a flexible structure in disciplinary issues. This article states and concludes that incomplete norms may affect the due process. The article starts expressing the nature of disciplinary law and its succinct application with respect to the right of due process.
\end{abstract}

Key words: Disciplinary law; due process right; legality principle; incomplete norms. 


\section{INTRODUCCIÓN}

El derecho disciplinario encuentra en el ordenamiento jurídico nacional su sustento primario en el artículo $6^{\circ}$. de la Constitución Política. La norma establece que los particulares solo son responsables ante las autoridades por infringir la Constitución y las leyes. Los servidores públicos lo son por la misma causa y por omisión o extralimitación en el ejercicio de sus funciones.

Es así como el servidor público tiene una doble vinculación con el Estado: la primera negativa, que comparte con los particulares, la cual lo hace responsable por infringir una norma. A esta se le suma una vinculación positiva, que condiciona sus actuaciones como operador del Estado, limitándolo a ejercer las actividades para las que se encuentra expresamente facultado. De actuar excediendo su competencia, se extralimitaría; de proceder faltando a ella, incurriría en una omisión (Madrid-Malo, 1998, pp. 76-77).

El derecho disciplinario hace uso de diferentes normativas contentivas de facultades y prohibiciones (estatutos, reglamentos, leyes), que tienen por objeto determinar las competencias y las faltas, y establecer las consecuencias de su infracción, con una particularidad que será el objeto de análisis de este trabajo: en asuntos disciplinarios la tipicidad de las faltas se halla consagrada, en gran medida, a través de tipos sancionatorios en blanco.

En materia disciplinaria, muchos de los tipos sancionatorios se caracterizan por carecer de una descripción estricta y precisa. Es el caso del tipo en blanco que no describe concretamente la infracción. Esto lo hace a través de la remisión a todas las disposiciones que consagren deberes, mandatos y prohibiciones aplicables a la persona objeto de un proceso disciplinario.

Pueden observarse en estos casos unas normas que establecen una prohibición abierta: no existe una descripción específica y precisa de la infracción y su consecuencia. Se da, por el contrario, una remisión en abstracto a otras normas para completar el tipo. No es dable asegurar que todos los tipos disciplinarios son de esta clase, pero se puede observar una tendencia mayor a hacer uso de estos en el derecho disciplinario.

Es así como para este trabajo se parte de la tesis que un tipo sancionatorio en blanco (abierto) en el derecho disciplinario puede devenir en una vulneración al derecho fundamental del debido proceso, en la medida que al operador jurídico disciplinario se le conmina a aplicar un margen valorativo excesivamente amplio para conformar el tipo que será atribuido en el proceso disciplinario, cuya máxima certeza se exige desde los preceptos del debido proceso y el derecho de defensa.

De este modo, esta reflexión tiene como objetivo verificar si los tipos sancionatorios en blanco atentan contra los postulados del debido proceso. Para esto, se acudió al examen de la doctrina especializada y la jurisprudencia colombiana con el fin de dilucidar la naturaleza del 
derecho disciplinario y así identificar los principios que rodean el acto de juzgar disciplinariamente; luego se revisó la categoría de tipo en blanco, definiendo su concepto, particularidades y uso en el derecho disciplinario; finalmente, se hace una aproximación al debido proceso como categoría jurídica y su relación con los tipos en blanco.

Tal esquema de investigación es reproducido en el presente artículo, donde primero se caracteriza el derecho disciplinario como rama autónoma del derecho, luego los tipos sancionatorios en blanco, continuando con los postulados del debido proceso, la relación de ambas categorías y, finalmente, se presentan las conclusiones.

\section{NATURALEZA DEL DERECHO DISCIPLINARIO}

La disciplina como concepto se relaciona con la actitud de una persona hacia su entorno. Se puede calificar desde una doble perspectiva: la interna como subordinación de los instintos a la razón, y la exterior con referencia al orden social (Mújica, 2005, p. 318).

Desde las ciencias pedagógicas se plantea que la disciplina como acto puede consistir en un ejercicio de coacción externa que regula y exige el cumplimiento de normas; igualmente, puede plantearse desde el ámbito formativo como estructurador de ritmos y hábitos en las personas que facilitan la convivencia (Gómez, 2006, p. 37).

En ese sentido, la disciplina vincula a las personas con ciertas reglas de conducta imprescindibles para el funcionamiento de cualquier comunidad coordinada, lo cual justifica la existencia de regímenes disciplinarios tanto en el ámbito público como en el privado para alcanzar determinados fines (Corte Constitucional, C-286/96).

El derecho disciplinario en el ámbito del derecho, ya sea considerado como subespecialidad de este o como un procedimiento especializado, se comenzó a aprehender teóricamente en la segunda mitad del siglo pasado, sin querer expresar con esto que este derecho, como realidad material, se limita a dicho espacio temporal.

Joan Manuel Trayter (1991, pp. 34-35) afirma que en el contexto ibérico nacen las primeras manifestaciones del derecho disciplinario en la Baja Edad Media con la aparición de los primeros aparatos burocráticos. Se atribuyeron a los oficiales reales ciertas competencias que devinieron en la instauración de un sistema de responsabilidad por los actos cometidos en el ejercicio de sus funciones y la imposibilidad para el rey de separar unilateralmente a los servidores de sus cargos.

Más adelante, en el período colonial, se establece una serie de instituciones con la finalidad de afianzar una gerencia eficaz, justa y leal de los funcionarios de la Corona en tierras iberoamericanas. Nacen la visita, el juicio de residencia, la pesquisa y la purga de taula ${ }^{1}$ como medios

La visita consistía en una inspección al funcionario o gobernante para estudiar su labor administrativa, con el juicio de residencia se exigían cuentas de la gestión al funcionario que entregaba con su car- 
de la Corona para controlar la gestión de los administradores en América (Trayter, 1991, p. 36).

Una segunda tesis ubica el nacimiento del derecho disciplinario con el advenimiento del Estado moderno. La expansión del Estado generó la necesidad de contar con un mayor y más especializado número de personas al servicio de la administración. La demanda no lograba cubrir la oferta, lo cual obligó a los príncipes a conceder prerrogativas económicas y judiciales a sus servidores con el fin de conservar los que tenían y atraer a los más preparados. Con esto se allana el camino para iniciar procesos que limitaban el poder discrecional de la autoridad (Nieto, 1970, pp. 44-45).

En los pueblos indígenas la disciplina se ha instaurado a través de sus autoridades tradicionales. Es así como en el caso de los pueblos andinos colombianos perviven instituciones de carácter prehispánico y colonial encargadas de establecer formas de control y de enjuiciar los comportamientos de sus miembros. No es un sistema centralizado, pues en la base coexisten diferentes sistemas de autoridad como los taitas, los chamanes, los médicos tradicionales que tienen potestades disciplinarias específicas (GómezValencia, 2006, pp. 684-687).

go, la pesquisa con la misma finalidad de la visita, pero impulsada a través de medios diferentes y la purga de taula que consistía en un juicio hecho a los oficiales reales por su gestión. Trayter (1991, pp. 36-52) afirma que cada instituto perseguía unos fines específicos, que devenían esencialmente en juicios penales.
Desde el ámbito legal se puede definir el derecho disciplinario como la serie de normas de carácter jurídicos dispuestas por el Estado que tienen como objetivo determinar los hechos ilícitos en los que pueden incurrir los funcionarios públicos al ejercer sus cargos, previendo las sanciones que puede imponer la Administración a través de un procedimiento administrativo específico (Trayter 1991, p. 27).

No obstante el consenso en cuanto a la definición del derecho disciplinario, se ha planteado la discusión doctrinal frente a su naturaleza, siendo objeto de debate las posturas que lo conciben como una rama del derecho penal, del derecho administrativo o, modernamente, como una disciplina autónoma. Esta discusión no es bizantina, ya que optar por una u otra posición conlleva aplicar principios totalmente diferenciales en el acto de juzgar disciplinariamente.

\subsection{Naturaleza penal}

Las primeras posturas dogmáticas ubican el derecho disciplinario como una prolongación del derecho penal. Se parte de la concepción que derecho penal, derecho penal administrativo y derecho disciplinario, entre otras, son especies del derecho sancionar o iuspuniendi del Estado (Gómez, 2012, p. 51), por lo cual son equiparables y los revisten los mismos principios.

Los dogmáticos más intransigentes llegaron a platear que el derecho disciplinario no era más que un anexo del derecho penal, del que hizo parte desde su nacimiento hasta tiempos más recientes. Es 
así como planteaban que en Alemania, hasta el siglo XVIII, el derecho disciplinario estaba inmerso en el derecho penal. Luego, en el siglo XIX, logran separarse, pero no para alcanzar su autonomía, sino para integrar el derecho público del Estado (Nieto, 1970, pp. 57-58).

Tal como observa Paul Laband, jurista alemán de finales del siglo XIX, el derecho disciplinario era entendido como el derecho penal de los funcionarios, la infracción disciplinaria era consideraba una variante de los delitos de naturaleza penal, y el procedimiento disciplinario, una especie de proceso penal (Nieto, 1970, p. 60).

Como efecto de plantear la naturaleza del derecho disciplinario desde el núcleo del derecho penal, se abre la discusión frente a la identidad entre infracción y delito como argumento en la defensa de la posición que destaca el parentesco entre ambas disciplinas.

Los ilícitos en materia penal y en materia administrativa son expresiones del poder punitivo del Estado (Úbeda, 2007, p. 991). Existe identidad sustancial entre delito e infracción administrativa, así como entre sus correlativos pena y sanción administrativa (Trayter, 1991, p. 123).

Posteriormente, con el nacimiento del Estado de derecho fundamentado en las posturas liberales, se origina la necesidad de hallar una distinción sustancial entre delito e infracción. En este contexto se planteó el delito como una acción ética y socialmente relevante digna de reproche, y la infracción como una acción irrelevante para la ética y la sociedad, que se agotaría en la desobediencia de mandatos y prohibiciones. La infracción no constituiría lesión o peligro de un bien jurídico, sino un traumatismo al interés de la Administración (Cerezo, 1975, pp. 161-164).

José Cerezo (1975, pp. 165-166), catedrático de derecho penal, sugiere que esta distinción es falaz. La sanción administrativa también corresponde a un juicio de valor ético y social, no habiendo fundamento lógico en la exclusión del instituto bien jurídico del derecho penal administrativo y por reflejo en el derecho disciplinario. Tanto el derecho penal como el derecho penal administrativo encuentran justificado su accionar en la gravedad del ilícito, habiendo solamente diferencias cuantitativas entre delito e infracción.

La concepción de derecho disciplinario como especialidad o agregado del derecho penal fue una postura planteada por las cortes colombianas. En este sentido se expresó la Corte Constitucional en la sentencia T-438 de 1992, indicando que si bien un amplio sector doctrinal establecía diferencias entre la responsabilidad civil, penal y administrativa, dicho tribunal hallaba que las garantías y los principios del derecho penal cobijaban la sanción disciplinaria. La esencia sancionatoria en ambas disciplinas implicaría que las categorías y garantías del derecho penal, que resulta más general, se aplicaran al derecho disciplinario, que posee una especialidad más determinada, pero de naturaleza igualmente sancionatoria. La pena se convertiría en el componente 
coactivo común en ambos derechos y por lo tanto, todas las garantías y principios del derecho penal se harían aplicables al derecho disciplinario.

En la sentencia T-438 de 1994, siguiendo los lineamientos de la sentencia antes comentada, concluyó la Corte que el derecho disciplinario era en esencia derecho penal administrativo, por lo que debería aplicársele los principios del derecho penal general. En este sentido agregó que el vocablo pena, del ahora derogado Decreto 100 de 1980 en su artículo 375, debería entenderse como cualquier represión formalizada del Estado.

El jurista colombiano Carlos Gómez Pavajeau (2004, pp. 88-89) resalta la sentencia del 27 de septiembre de 1960 de la Corte Suprema de Justicia, Sala Penal, que equipara el derecho disciplinario para abogados (para entonces Ley 69 de 1945) con el derecho penal administrativo, considerándolo una especie de derecho penal, por lo cual, deberían aplicársele todas sus reglas y consecuencias. El derecho disciplinario se agruparía en una rama de la Administración Pública con base en un criterio de oportunidad, pero guardaría la sustancia, naturaleza y principios del derecho penal. La Sala Penal llegaría a concluir que las sanciones disciplinarias son penales en estricto sentido, ya sea que provengan de un derecho penal disciplinario autónomo o bien del derecho penal.

Para la misma época se observó una diferente enunciación, pero se llegaba a la conclusión de las equivalencias entre ambas disciplinas. Así lo expresó la Corte Suprema de Justicia, Sala de Casación Penal, en sentencia del 4 de marzo de 1991. En principio aceptó la naturaleza heterogénea entre la infracción penal y la disciplinaria, pero reconoció su similitud, por lo que estableció que en ambas se debían seguir los postulados de la legalidad, la tipicidad, la antijuridicidad y la culpabilidad (Gómez, 2004, p. 90).

\subsection{Naturaleza administrativa}

La tesis administrativista surge como evolución a los postulados de Laband. Este jurista, planteaba que hasta finales del siglo XIX en Alemania el derecho disciplinario era entendido como el derecho penal de los funcionarios. Propone que a pesar de la similitud externa y formal entre ambos derechos, el concepto de derecho disciplinario no puede construirse desde el derecho penal, si no desde el derecho civil. Para el autor, la infracción no es expresión del poder sancionador del Estado, sino que es una falta contractual apoyada en una relación de poder. Es así como la acción para exigir el cumplimiento de un contrato se convierte, en el ámbito administrativo, en coacción con base en la relación de servicio (Nieto, 1970, p. 60).

Esta postura se supera históricamente cuando las legislaciones establecen que los funcionarios se encuentran en una relación estatutaria y reglamentaria respecto de la Administración. Pero los administrativistas recogen las ideas sobre la relación de poder para construir su propuesta doctrinal (Nieto, 1970, p. 62). 
En ese sentido, Pavajeau (2004, pp. 44-58) expone cómo los doctrinantes administrativos proponen estudiar el fenómeno por fases: la fase de la arbitrariedad que se caracterizaba por la completa discrecionalidad de la Administración para determinar las infracciones y las sanciones; la fase moderna que procura por una facultad reglada que determine el hecho y la sanción y, la fase de la legalidad, donde la ley determina el régimen disciplinario aplicable a los servidores.

Como se observa, la nota característica para los administrativistas, al contrario que los penalistas, no radica en el poder punitivo del Estado o la naturaleza de la sanción. El derecho disciplinario se constituiría, en cambio, a partir de una relación especial entre la Administración y el servidor que dota al primero de ciertas prerrogativas, en la actualidad regladas, para determinar los hechos constitutivos de infracción, las sanciones y el procedimiento disciplinario.

Igual que ocurrió con la teoría de la naturaleza penal, las cortes colombianas también tuvieron la oportunidad de abordar la tesis sobre la naturaleza administrativa. El Consejo de Estado, Sección Segunda, en sentencia del 3 de noviembre de 1995 planteó como el derecho disciplinario incorpora normas que encuentran su causa en la relación del Estado con sus funcionarios, donde se determinan las faltas, su sanción y las autoridades para imponerlas. La Corporación aclara que el derecho disciplinario administrativo no se restringe a la estructura del derecho penal común. Aquel derecho busca la moralidad, la legalidad, la imparcialidad, la responsabilidad y la eficiencia en el servicio público; es así como los elementos de imputabilidad y culpabilidad no podrían ser aplicados como si se tratara de un asunto estrictamente penal.

\subsection{Naturaleza autónoma}

La propuesta de la naturaleza autónoma del derecho disciplinario surge como un avance teórico a los planteamientos de la relación de poder observada en el vínculo Estado-servidor y destacada por los administrativistas. Se caracteriza como una relación especial de sujeción, que se formula como una categoría jurídica que concierne exclusivamente a los servidores públicos en su relación con la Administración, donde se armonizan el principio del interés general, los principios de la función pública, los fines del Estado y las garantías y derechos fundamentales en el perímetro del derecho disciplinario (Gómez, 2012, pp. 59-60).

La relación especial de sujeción se identifica como el dispositivo que concede a la Administración facultades extraordinarias para ejercer sus potestades. La sujeción implica una situación jurídica pasiva en relación con los poderes de la Administración: el Estado, a través de sus órganos administrativos, se constituye en el sujeto activo, en contraposición del sujeto pasivo que siempre será un servidor público. Cabe resaltar que la facultad intervencionista del Estado cobija a los particulares que ejercen funciones públicas, a algunas profesiones liberales y ciertas actividades especiales (Gil, 2009, pp. 178-179). 
Otto Mayer y el referido Paul Laband, juristas alemanes, proponen las ideas fundamentales en la formulación teórica del concepto de relación especial de sujeción, basados en las nociones de dependencia y libertad restringida asociadas a la persona que ingresa a la Administración Pública. Mayer expone que esta relación se caracteriza por un vínculo desigual con el Estado; una dependencia a favor de la Administración; un estado de derechos y libertad restringidos y solo necesarios para lograr la eficacia de la Administración; una restricción fundamentada en la ley; un poder jurídico en cabeza de la Administración que le permite disciplinar al servidor para mejorar el servicio (Gil, 2009, pp. 185-187).

Actualmente, estas prerrogativas son regladas a través de la ley y la jurisprudencia, para evitar el desbordamiento de las potestades del Estado que deriven en arbitrariedad y abuso del derecho.

El segundo pilar sobre el que descansa la teoría de la naturaleza autónoma, y que se conecta con la propuesta de la relación especial de sujeción, se constituye a partir de los fines del Estado, los cuales se alcanzan, esencialmente, a través del ejercicio de los deberes funcionales de los servidores. Como lo resalta Gómez Pavajeau (2011) "[... de manera clara se ha dicho que la función del derecho penal es la protección de los bienes jurídicos, y la del derecho disciplinario, el aseguramiento de los deberes funcionales" (p. 125).

En este sentido, se ha ubicado la jurisprudencia de la Corte Constitucional, que finalmente optó por considerar el derecho disciplinario como una disciplina autónoma. En sentencia C-244 de 1996, abordando el tema a través del contraste con el derecho penal, advierte la Corporación que se trata de disciplinas heterogéneas. La acción disciplinaria, expresa, se origina dentro de la relación subordinada existente entre el servidor y la Administración en el contorno de la función pública, originada por la inobservancia de un deber, de una prohibición, por la omisión o extralimitación de funciones, entre otros. Resalta que la acción disciplinaria busca garantizar el buen funcionamiento de la Administración, así como su moralidad y prestigio.

En el mismo sentido cabe destacar la sentencia C-125 de 2003, donde el Tribunal Constitucional enfatiza que el Estado, ahora de carácter social determinado en la Constitución Política de 1991, impuso al aparato estatal nuevos objetivos, concibiéndolo como promotor de la dinámica social a través del ejercicio de nuevas actividades y funciones para efectivizar los derechos fundamentales. Las nuevas actividades de la Administración obligan a que su gestión sea ejercida eficazmente y para alcanzarlo se lo dotó con ciertas facultades de sanción.

Es así como frente a la imputación disciplinaria, la Corte Constitucional ha determinado que esta se basa en la obligación de alcanzar los fines del Estado que dan sentido a la función pública ejercida por los servidores. El servidor está sometido a la Constitución y la ley, su servicio se concibe en relación con el interés general 
y con los principios de la función pública. Los deberes del servidor nacen de su vínculo con el Estado, y con su desatención se afectan los fines estatales; por lo tanto, la falta disciplinaria se remite a la "infracción sustancial del deber funcional a cargo del servidor público o del particular que cumple funciones públicas" (C-252/03).

En sentencia C-242 de 2010 la Corte puntualiza cómo el derecho disciplinario es una manifestación de la potestad punitiva del Estado. Señala explícitamente que es un derecho autónomo con finalidades exclusivas como son el buen funcionamiento de los órganos y ramas del Estado y el adecuado desempeño de las personas que ejercen la función pública.

La facultad sancionadora del Estado dirigida a asegurar el adecuado funcionamiento de la Administración Pública está en cabeza de la Procuraduría General de la Nación ${ }^{2}$. El derecho disciplinario, como especie del derecho sancionador, ha llegado a "obtener un espacio autónomo e independiente (...) dirigido a la protección de la organización y funcionamiento del Estado" (Botero, Marín, Maury, 2015, p. 153-154) para asegurar que se cumplan los fines del Estado por medio del control de los actos oficiales de los servidores públicos y de los particulares que ejerzan función pública (Botero, et al; 2015, p. 154).

2 La Constitución Política de Colombia, en el artículo 277, establece que la Procuraduría General de la Nación tiene entre sus funciones velar por el ejercicio diligente y eficiente de las funciones administrativas, ejercer vigilancia de la conducta oficial de las personas que desempeñen funciones públicas y ejercer, preferentemente, el poder disciplinario.
Una vez verificada la naturaleza del derecho disciplinario, se abordará uno de sus elementos de manifestación normativa, esto es, el tipo sancionatorio en blanco.

\section{TIPOS SANCIONATORIOS EN BLANCO}

Abarcar el estudio de los tipos en blanco exige un primer acercamiento a la categoría jurídica de tipo. Esta ha sido estudiada en extenso por la disciplina penal, especialmente el capítulo asignado a la teoría del delito. Frente a su definición se han planteado, entre otros, los siguientes conceptos:

Agudelo Betancur (2010), desde el sistema clásico, percibe el tipo como "la mera descripción de las características externas de la acción" (p. 60).

Folchi (1960) lo califica como "la abstracción concreta de lo injusto recogido y descrito en la ley" (p. 22).

Herrera Echeverri (2004, p. 33) comprende el tipo como un modelo materializado en la ley que fija las conductas de relevancia penal.

Jiménez de Asúa (1995) considera el tipo como una abstracción específica que hace el legislador en la definición de un hecho, catalogándolo como delito a través de la ley.

Muñoz Conde (2005, p. 31) dice que el tipo es la descripción de una conducta prohibida contenida en el supuesto de hecho de las normas penales. 
Reyes Echandía (1967, p. 15) define el tipo en términos de una descripción abstracta hecha por el legislador a la cual asigna una sanción penal.

Zaffaroni (2002) define los tipos como "las fórmulas que usa la ley para señalar los pragmas conflictivos cuyas acciones amenaza con pena" (p. 412).

Velásquez (2007, p. 261), siguiendo a Zaffaroni, lo define como un instrumento legal de naturaleza descriptiva a través del cual se individualizan conductas humanas susceptibles de ser sancionadas.

Se tiene entonces que el tipo es una descripción en abstracto que hace el legislador de ciertas conductas o acciones que decide calificar como reprochables, asignándoles una consecuencia jurídica. Es así como el tipo sancionatorio determina que "El que matare a otro, incurrirá en prisión de doscientos ocho (208) a cuatrocientos cincuenta (450) meses" (Art. 103, Ley 599 de 2000); "El servidor público que abusando de sus funciones, prive a otro de su libertad, incurrirá en prisión de cuarenta y ocho (48) a noventa (90) meses." (Art. 174, Ley 599 de 2000). Esto sucede con los demás enunciados consagrados esencialmente en la parte especial de los códigos penales.

\subsection{Definición y naturaleza de los tipos en blanco}

En consideración de lo anterior, se colige que la norma penal tiene una estructura unitaria, pero compuesta por dos elementos: el precepto, que se configura como prohibición o mandato, y la sanción que determina las consecuencias jurídicas originadas de la violación del precepto (Maggiore, 2000, p. 141). Empero, existen casos en que la conducta si bien se encuentra expresamente consagrada en la ley, no está completamente descrita en el tipo (Boettiger, 2009, p. 589). En estos casos se está en presencia de los denominados por la doctrina como tipos en blanco.

Se le atribuye al alemán Karl Binding ser el primer jurista en estudiar tal fenómeno, acuñando la expresión blanketstrafgesetze para referirse a las normas penales en las que se determina la sanción, pero cuyo precepto se encuentra establecido como una prohibición genérica, para luego ser definida concretamente por un reglamento, una orden ejecutiva u otra norma (Reyes Echandía, 1967, p. 140).

Fernando Velásquez (2007, pp. 304-305) no está de acuerdo con el término tipo en blanco, ya que asegura da a entender una ausencia de tipificación para referirse a los casos en los que el supuesto de hecho se encuentra consagrado de forma total o parcial en una norma por fuera del ámbito penal.

Fernández Carlier (1999, p. 272), desde un estudio de la autonomía del tipo, resalta que el tipo en blanco carece de esta en su aplicación. El empleo de estos tipos sancionatorios obliga que la conducta sea concretada en otra norma que se convierte en su complemento. Por lo tanto, la adecuación es indirecta ya que debe hacerse en dos normas: el tipo en blanco 
y su complemento, a través de un reenvío. Asegura el mismo autor que el precepto, entendido como la enunciación de la conducta típica, se construye por medio de la integración de dos normas vigentes al momento de ejecutarse la conducta. Al unirse el tipo en blanco y su complemento, alcanzarían la eficacia de un tipo sancionatorio autónomo. La existencia de estos tipos obedece a la variedad de temas que son objeto de protección penal y las múltiples conductas que pueden tratarse. Resalta, entre estos, los delitos económicos, contra el medio ambiente y la violación a las comunicaciones (pp. 272-273).

En el texto La ley penal en blanco, de Enrique Cury (1988, pp. 39-40), el tipo en blanco o ley penal en blanco, es caracterizado como una técnica legislativa de reenvío. El tipo en blanco sería aquella que remite el complemento de su precepto a una disposición normativa distinta. Según el autor, la ley penal puede ser propia cuando se complementa con una norma de inferior jerarquía, e impropia cuando lo hace con una norma equivalente. Asimismo, el reenvío puede darse entre los propios artículos de la norma.

\subsection{Los tipos en blanco en el derecho disciplinario}

En el marco de las observaciones anteriores, se observa que las relaciones generales de sujeción, es decir, las relaciones de los particulares con el Estado se rigen por el derecho fundamental de la libertad, donde aquellos pueden hacer todo lo que no les esté expresamente prohibido. Por lo tanto, el legislador se pronuncia por vía negativa dejando expresos los hechos prohibidos, generalmente a través de tipos cerrados (Gómez 2012, p. 66).

En materia de las relaciones especiales de sujeción, aquella que se predica del servidor público con el Estado, la lógica se invierte, ya que el servidor, por mandato constitucional, solo puede hacer aquello que le está expresamente permitido. Esto se concreta a través de un catálogo de funciones y deberes, contrapuesto a las omisiones y extralimitaciones en que pueden incurrir. De este modo, la tipicidad en materia disciplinaria, se construye a partir del examen de todas las disposiciones jurídicas que contemplen funciones, deberes, órdenes, limitaciones y prohibiciones a los servidores públicos (Quintero, 2011, p. 8).

El fenómeno descrito impide técnicamente al legislador que pueda definir en un código todas las conductas prohibidas, ya que cada función, deber, orden, limitación y prohibición serían susceptibles de una sanción por acción, omisión o extralimitación. Luego, debe limitarse a señalar algunas conductas relevantes de la gama que se le presenta; las demás deberá regularlas con fórmulas abstractas (Gómez, 2004, pp. 286-287) y a través de los tipos en blanco.

Este es el caso del derecho disciplinario, donde el legislador ha optado por hacer uso de la técnica de reenvío, propia de los tipos en blanco, para establecer las faltas disciplinarias de los servidores públicos. Si bien no todos los tipos disciplinarios 
son de esta naturaleza, se halla una tendencia mayor a hacer uso de ellos en esta especialidad.

En este sentido se puede observar, a manera de ejemplo, el artículo 35 de la Ley 734 de 2002 que prohíbe a los servidores públicos incumplir los deberes y abusar de los derechos consagrados en la Constitución, leyes, tratados y demás. El artículo 48 numeral $1^{\circ}$., ibídem, que determina como falta gravísima "Realizar objetivamente una descripción típica consagrada en la ley como delito sancionable a título de dolo [...]". El artículo 48 numeral $7^{\circ}$. de la misma ley, que determina como falta gravísima incurrir en violaciones graves al derecho internacional humanitario.

El uso de tipos en blanco se encuentra materializado en diferentes reglamentos disciplinarios de las más diversas instituciones del Estado. Puede verificarse el artículo 247 del Acuerdo 01 de 1981 o Reglamento Estudiantil de la Universidad de Antioquia que consagra como falta disciplinaria "las conductas que atentan contra la ley, los estatutos y reglamentos universitarios, entre otras".

En el ámbito privado también se observa el fenómeno. Es el caso del capítulo IX del Estatuto Profesoral de la Universidad de los Andes que exige a los docentes el cumplimiento de los deberes de dicho estatuto, así como las normas previstas en el reglamento de trabajo y el contrato individual celebrado con la Universidad, cuya inobservancia, indica, puede acarrear responsabilidades disciplinarias.
El derecho disciplinario, y por tanto el uso de los tipos en blanco, es aplicable a diferentes organizaciones, independientemente de la naturaleza de la sociedad. Obsérvese el artículo 64 literal C del Reglamento Interno de Trabajo de BANCOLOMBIA S. A; que determina como falta disciplinaria el incumplimiento "de las demás obligaciones o prohibiciones legales, contractuales o reglamentarias [...]". Así mismo, el artículo 104, numeral $6^{\circ}$ del Reglamento Interno de Trabajo de Servicios Financieros S.A, compañía de financiamiento, que constituye como justa causa para dar por terminado unilateralmente el contrato de trabajo la violación grave de las obligaciones o prohibiciones, así como la falta a las convenciones colectivas, fallos arbitrales, contratos individuales o el propio reglamento 3 .

En múltiples ocasiones la Corte Constitucional se ha pronunciado sobre el empleo de los tipos en blanco, dotándolos de validez. En la sentencia C-127 de 1993 la Corte hace sus primeros estudios sobre este tema. Indicó que los tipos en blanco son admisibles constitucionalmente y se adecuan al principio de tipicidad siempre que el reenvío normativo permita al operador jurídico determinar la

\footnotetext{
Juan Gabriel Tejada (2016) concluye que el poder de dirección del empleador lo faculta para dar instrucciones y aplicar sanciones disciplinarias a sus trabajadores. Facultad que no es ilimitada. El proceso disciplinario, en las relaciones privadas, debe respetar la Constitución y la ley para evitar la arbitrariedad y abuso del empleador. La subordinación no implica el poder despótico del empleador y éste, en el ámbito disciplinario, se contiene a través de etapas procesales en donde se observen los principios de legalidad y congruencia.
} 
conducta reprochable y la sanción que le corresponda.

En sentencia C-427 de 1994 la Corte advirtió que, a diferencia del derecho penal, en el derecho disciplinario el fallador cuenta con un margen de valoración y de individualización de las faltas más amplio, debido a los diversos comportamientos que pueden afectar los propósitos de la función pública y del régimen disciplinario.

Frente a los tipos disciplinarios resalta la Corporación que estos pueden ser incompletos y carecer de autonomía, haciendo necesario remitirse a otras normas donde se regulan concretamente los deberes, las obligaciones, las funciones y las prohibiciones de los servidores públicos ${ }^{4}$.

La Corte Constitucional es reiterativa en justificar la validez de los tipos en blanco en el derecho disciplinario dada la necesidad de salvaguardar el principio de eficiencia de la función pública. Ha dicho que una aplicación estricta del principio de tipicidad obligaría a describir en el tipo disciplinario todas las normas que consagran mandatos, deberes y prohibiciones. Esta exigencia, razona la Corte, se convertiría en un obstáculo para que la función disciplinaria se realizara de forma coherente, ordenada y sistemática, afectando su gestión ${ }^{5}$.

$4 \quad$ Al respecto se puede consultar las sentencias C-244 de 1996, C-564 de 2000, C-404 de 2001 y C-181 de 2002, entre otras.

5 Esta línea jurisprudencial puede constarse en las sentencias C-948 de 2002, T-1093 de 2004, C-818 de 2005, C-762 de 2009, C-030 de 2012. Además de las sentencias C-599 de 1999, C-404 de 2001, C-252 de 2003, C-431 de 2004.
Ahora bien, para verificar si los tipos sancionatorios en blanco atentan el debido proceso, se continuará con la caracterización de esta categoría jurídica y la relación entre ambas.

\section{DEBIDO PROCESO}

\subsection{Aproximación conceptual}

En el contexto occidental, la conformación del Estado moderno surge como contraposición al Estado absoluto. Es así como el Estado de derecho nace a finales del siglo XVIII y logró su consolidación en el siglo XIX, con vigencia en la actualidad. El Estado de derecho persigue, entre otros, proteger, garantizar y realizar los derechos humanos y las libertades fundamentales (García Ricci, 2011, pp. 21-37).

La institución del debido proceso se vinculó de forma natural dentro del desarrollo del Estado de derecho. Sin embargo, su génesis se remonta al siglo XIII en Inglaterra con el desarrollo del principio due process of law o el debido proceso de la ley, asentado en la Carta Magna inglesa del año 1215. Su objetivo principal fue el de contener las actuaciones del Estado en cabeza del rey cuando pretendía limitar los derechos fundamentales a la vida, la libertad y la propiedad de los ciudadanos ingleses. El due process of law implicaría un juicio limpio que minimizara el riesgo de una resolución caprichosa (Esparza, 1994, pp. 84-93).

La Carta Magna fue el nombre que se le otorgó al escrito que los barones normandos obligaron a firmar al rey Juan I de Inglaterra conocido como Juan sin Tierra 
por los alcances del texto, para el reconocimiento y protección de los derechos de aquellos. En su artículo 39 prohíbe el arresto, la detención, el exilio, el despojo de la propiedad de ningún hombre libre, salvo un juicio legal de sus pares o por la ley del reino. Adicionalmente, en su artículo 40, prohíbe el retraso y la denegación de justicia ${ }^{6}$. De esta forma se reconoce la existencia de unos derechos susceptibles de protección frente a los actos del Estado.

En Alemania el principio del debido proceso se distingue como Faires Verfahren o juicio justo, de origen y arraigo del derecho procesal. Implica que el proceso debe estar diseñado y aplicado conforme a las exigencias del Estado de derecho. Regula los órganos encargados de crear las normas procesales, con especial énfasis en la autolimitación del poder estatal que debe ser limpio o fair. Implica, entre otros, unas leyes claras frente a las facultades y límites de los órganos y agentes del Estado, el derecho de defensa y la igualdad de armas. La jurisprudencia alemana, dotando de contenido el principio del debido proceso, ha señalado que atenta contra el Faires Verfahren todo acto de

6 Su texto en inglés moderno ha sido transcrito por la British Library -Biblioteca Nacional del Reino Unido- en los siguientes términos:

39) No free man shall be seized or imprisoned, or stripped of his rights or possessions, or outlawed or exiled, or deprived of his standing in any way, nor will we proceed with force against him, or send others to do so, except by the lawful judgment of his equals or by the law of the land.

(40) To no one will we sell, to no one deny or delay right or justice.

El documento en su integridad puede consultarse en http://www.bl.uk/learning/timeline/item 95692. html abusividad por parte del Estado. Haría parte del debido proceso la presunción de inocencia, el derecho de audiencia, el derecho a la información, el derecho a un proceso rápido, a la prueba lícita, a guardar silencio, a la defensa, a la ayuda de un intérprete gratuito (Esparza, 1994, pp. 166-191).

Actualmente, el debido proceso posee rango de derecho fundamental, que demanda la sujeción de los procedimientos a las normas jurídicas, asegurando la igualdad y el debate. El jurista Martín Agudelo (2007) resalta que el debido proceso se compone de dos garantías especiales: la legalidad del juez y la legalidad de la audiencia. Es así como el debido proceso estaría constituido por
El derecho fundamental al juez director, exclusivo, natural o competente, independiente e im- parcial; el derecho fundamental a la audiencia o a ser oído en un término razonable y en igualdad de condiciones con los demás participantes; el derecho funda- mental a la forma previamente establecida en la ley procesal; el derecho fundamental a que el proceso procese exclusivamente pretensión procesal ajustada al derecho sustancial preexistente (p. 17).

Iñaki Esparza (1994), quien en sus palabras no pretende formular una lista cerrada, observa que el debido proceso está compuesto por las siguientes garantías y derechos: motivación de las resoluciones, juez imparcial, derecho a la doble instancia, el principio pro actione, principio 
de intangibilidad de las resoluciones judiciales firmes, non bis in idem, gratuidad de la justicia, habeas corpus, lealtad y buena fe, conservación parcial del acto (pp. 320-326).

En una relación de debido proceso y acceso a la justicia, Eduardo Cifuentes (1999) recalca que hace parte de su núcleo esencial

\begin{abstract}
El acceso a la administración de justicia (tutela judicial efectiva); el derecho de defensa; el derecho a la defensa técnica; la favorabilidad penal; el derecho a la presunción de inocencia; derecho a ser juzgado ante juez o tribunal competente según previa determinación hecha por la ley; derecho a un proceso (público) sin dilaciones injustificadas; el derecho a la prueba; el derecho a la valoración no arbitraria de la prueba; el derecho a no ser juzgado dos veces por el mismo hecho (pp. 275-276).
\end{abstract}

Se hace imprescindible subrayar el carácter dinámico y expansivo del principio del debido proceso, que continuamente va incorporando derechos y garantías del ciudadano. Como lo manifiesta la Corte Interamericana de Derechos Humanos, el debido proceso se constituye en límite a la actividad del Estado y hace referencia al conjunto de requisitos que deben ser observados durante las instancias procesales a efectos de que las personas puedan defenderse adecuadamente ante cualquier acto del Estado que pueda afectar sus derechos (García Ramírez, 2006, p. 667).
Beatriz Quintero (2002, pp. 78-80) anuncia que el tema del debido proceso también ha sido abordado desde la filosofía con autores como Kant, Habermas y John Rawls. Concluye que el debido proceso busca descartar la irracionalidad en el racionamiento jurídico para reforzar la idea del debido proceso como un instrumento que promueve un derecho legítimo. Con el debido proceso, insinúa, es más probable acercarse al ideal del derecho justo.

\subsection{El principio de legalidad como manifestación del debido proceso}

El Estado de derecho descansa igualmente sobre el pilar del principio de legalidad, referido a las libertades de la persona y al límite impuesto a las autoridades estatales, en la medida que estas solo podrán actuar con fundamento en una norma legal. Este principio garantiza al ciudadano una libertad de acción, en la medida que tiene claro cuáles comportamientos son objeto de reproche estatal.

Esta premisa tiene su origen en la Ilustración como un postulado político contra la arbitrariedad y el abuso del poder del Estado. Conlleva la obligación de sus órganos a desistir de la prerrogativa de sancionar a una persona sin una ley previa que describa el comportamiento sancionable (Barbosa, 2005, pp. 109-111).

El Estado y el derecho deben justificar su actuar conforme a los intereses y bienes que promulgan proteger. En el Estado de derecho la facultad para describir delitos y castigarlos está sometida a la ley. El principio de legalidad, desde el plano 
formal, prescribe que todos los poderes públicos están subordinados a la ley. Las leyes generales y abstractas instruyen su ejercicio, que puede ser objeto de control. Desde el plano sustancial, los poderes públicos deben garantizar los derechos fundamentales, prohibiéndoseles limitar la libertad de los ciudadanos, además de la obligación de satisfacer sus derechos sociales (Ferrajoli, 1995, pp. 851 857).

En principio, el aforismo nullum crime, nulla poena sine lege scripta, stricta, certa e praevia pareciera recoger las máximas de los postulados liberales, que el jurista Enrique Cury (1988, pp. 10-18) descompone en los siguientes factores:

Nulle poena sine lege praevia. Garantía del ciudadano que le asegura que solamente podrá ser castigado cuando la ley le ha advertido previamente que el hecho por él ejecutado se configura en delito y, por lo tanto, es amenazado con la imposición de una pena.

Nulle poena sine lege stricta. El ciudadano tiene la garantía que se le castigará si actúa de forma determinada u omite comportarse de la forma en que la ley exige, asegurándole que no se dará ningún reproche si hace o deja de hacer algo similar, pero diferente a aquello que se le prohíbe o prescribe.

Nulle poena sine lege scripta. La determinación del castigo, que se traduce en la afectación a bienes básicos fundamentales debe provenir del órgano que representa al soberano, por lo tanto, debe estar plasmado en una ley en sentido estricto.

\subsection{Los tipos en blanco y el debido proceso}

El derecho disciplinario, como derecho sancionador especial y autónomo, ha sido objeto de una regulación más laxa frente a la construcción de los tipos disciplinarios que informan las acciones $u$ omisiones susceptibles de reproche por parte del Estado a sus servidores, y por extensión, a otras relaciones donde se advierte una relación particular de sujeción.

Este fenómeno, como se indicó, ha sido refrendado por el Tribunal Constitucional, que argumenta cómo el derecho disciplinario promueve los fines del Estado al exigir conductas especiales de sus servidores, y recalca la falta de una técnica legislativa más óptima para formar los tipos disciplinarios. Sin embargo, dichas razones carecen de fortaleza al hacer una ponderación del tipo en blanco frente al derecho fundamental al debido proceso y al principio de legalidad.

Un proceso disciplinario basado en un tipo indeterminado genera un conflicto frente a la seguridad jurídica y la regla de certeza que deben regir cualquier disposición normativa donde el ciudadano encuentra como su contraparte cualquier organismo del Estado o un sujeto de derecho que se encuentra en una posición privilegiada frente a él, como lo pueden ser las instituciones de educación o su empleador.

El derecho al debido proceso y a la defensa exigen claridad en los tipos disciplinarios, delimitando claramente las conductas sobre las que recae un re- 
proche legal. Por lo tanto, el tipo debe garantizarle que solamente será objeto de un proceso disciplinario cuando la norma le advierte, previamente, que un hecho determinado u objetivamente determinable es susceptible de sanción. La determinación del tipo le debe asegurar que solo será sancionado si actúa de esa forma determinada, y que no se dará ningún reproche si hace o deja de hacer algo similar, pero diferente a aquello que se le prohíbe. Adicionalmente, el tipo disciplinario debería estar recogido en un solo cuerpo normativo expedido por el órgano que cuente con la legitimidad para hacerlo.

Mientras el tipo disciplinario no cumpla con esos requisitos, se estará frente a un evento que escapa a la contención que antaño se intentó activar frente al Estado, imponiéndole el deber de someter sus actuaciones a las normas preestablecidas que garantizarán un debido proceso, la seguridad jurídica y la certeza de cara a los actos del establecimiento, para evitar que su accionar se configurará arbitrario y en un atentado contra los derechos e intereses de los ciudadanos.

\section{CONCLUSIONES}

El derecho disciplinario en Colombia es caracterizado como un derecho autónomo; por lo tanto, sus principios y garantías no son las exclusivas del derecho penal o del derecho administrativo.

La evolución jurisprudencial y doctrinaria ha elegido reconocer su naturaleza autónoma basada en la relación especial de sujeción y en los fines del Estado. Esta postura resuelve el asunto de su naturaleza al legitimar la potestad disciplinaria del Estado, pero deja inconclusa la definición de las garantías del sujeto disciplinable.

El tipo sancionatorio en blanco es una técnica de tipificación diseñada por la imposibilidad de acoger en una sola normativa todos y cada uno de los deberes, mandatos y prohibiciones que pueden ser susceptibles de sanción por desacato del sujeto disciplinable, ya sea por acción, omisión o extralimitación en sus funciones.

Frente al uso de los tipos sancionatorios en blanco, hay una falta total de reglas de remisión ciertas que permitan al sujeto disciplinable tener la claridad de que un hecho determinado u objetivamente determinable puede ser objeto de sanción.

Un tipo sancionatorio incompleto como lo es el tipo en blanco, sumado a la falta de reglas de remisión ciertas para completarlo, resulta atentatorio del derecho al debido proceso en su expresión del principio de legalidad.

Procurar una regulación precisa del tipo disciplinario fomentaría la legalidad y legitimidad de las actuaciones del Estado o de quien ejerza como juzgador. Cada ciudadano, sea particular o servidor público, es un sujeto de derecho, y por lo tanto, debe estar cobijado por las premisas del derecho fundamental al debido proceso y del principio legalidad que impidan cualquier posibilidad de abuso o arbitrariedad en los actos del órgano disciplinante. 


\section{REFERENCIAS BIBLIOGRÁFICAS}

Agudelo Betancur, N. (2010). Curso de derecho penal. Medellín: Ediciones Nuevo Foro.

Agudelo Ramírez, M. (2007). El proceso jurisdiccional. Medellín: Comlibros.

Barbosa Castillo, G. (2005). Principio de legalidad y proceso penal. Derecho Penal y Criminología, 26 (78): 109-123.

Botero, J., Marín, J., y Maury, J. (2015). Alcances y límites al control de los actos administrativos de carácter disciplinario ejercido por el Consejo de Estado de Colombia. Nuevo Derecho, 11 (17): 153-174.

Boettiger Philipps, C. (2009). El derecho administrativo sancionador en la jurisprudencia del Tribunal Constitucional. Revista Actualidad Jurídica, (20): 577-596.

Cerezo Mir, J. (1975). Límites entre el derecho penal y el derecho administrativo. Anuario de Derecho Penal y Ciencias Penales, 28 (2): 159-172.

Cifuentes Muñoz, E. (1999). Acceso a la justicia y debido proceso en Colombia (síntesis de la doctrina constitucional). Anuario Iberoamericano de Justicia Constitucional, (3): 271-318.

Congreso de la República de Colombia, Ley 599, 24 de julio de 2000

Congreso de la República de Colombia, Ley 734, 5 de febrero de 2002

Consejo de Estado, Radicación 1443, 3 de noviembre (1995)

Corte Constitucional Colombia, Sentencia T-438 (1992)

Corte Constitucional Colombia, Sentencia C-127 (1993)

Corte Constitucional Colombia, Sentencia C-427 (1994)
Corte Constitucional Colombia, Sentencia T-438 (1994)

Corte Constitucional Colombia, Sentencia C-244 (1996)

Corte Constitucional Colombia, Sentencia C-286 (1996)

Corte Constitucional Colombia, Sentencia C-599 (1999)

Corte Constitucional Colombia, Sentencia C-564 (2000)

Corte Constitucional Colombia, Sentencia C-404 (2001)

Corte Constitucional Colombia, Sentencia C-181 (2002)

Corte Constitucional Colombia, Sentencia C-948 (2002)

Corte Constitucional Colombia, Sentencia C-125 (2003)

Corte Constitucional Colombia, Sentencia C-252 (2003)

Corte Constitucional Colombia, Sentencia C-431 (2004)

Corte Constitucional Colombia, Sentencia T-1093 (2004)

Corte Constitucional Colombia, Sentencia C-818 (2005)

Corte Constitucional Colombia, Sentencia C-762 (2009)

Corte Constitucional Colombia, Sentencia C-242 (2010)

Corte Constitucional Colombia, Sentencia C-030 (2012)

Cury, E. (1988). La ley penal en blanco. Bogotá: Temis.

Esparza Leibar, I. (1994). El principio del proceso debido. Tesis Doctoral, doctorado en Derecho. 
Valencia, España. Universidad Jaime I. Recuperado en http://www.tesisenred.net/ handle/10803/10427 [Consulta el 22/06/2012].

Fernández Carlier, E. (1999). Estructura de la tipicidad penal. Bogotá: Ediciones jurídicas Gustavo Ibáñez.

Ferrajoli, L. (1995). Derecho y razón: teoría del garantismo penal. Madrid: Editorial Trotta.

Folchi, M. O. (1960). La importancia de la tipicidad en el derecho penal. Buenos Aires: Depalma.

García Ramírez, S. (2006). El debido proceso. Concepto general y regulación en la Convención Americana sobre Derechos Humanos. Boletín Mexicano de Derecho Comparado, 34 (117): 637-670.

García Ricci, D. (2011). Estado de Derecho y principio de legalidad. México D. F. Comisión Nacional de los Derechos Humanos. Consultado en http://stj.col.gob.mx/dh/html/biblioteca/ descargables/pdf/3/iii/8.pdf

Gil García, L. M. (2009). Relaciones especiales de sujeción. Aproximación histórica al concepto. Prolegómenos: Derecho y Valores, 12 (23): 177-192.

Gómez, S. M. (2006). Educación, disciplina y violencia. Consideraciones teóricas e interpretaciones a partir de una realidad institucional. Diálogos Pedagógicos, 4 (8): 35-52.

Gómez Pavajeau, C. A. (2004). Dogmática del derecho disciplinario. Bogotá: Universidad Externado de Colombia.

Gómez Pavajeau, C. A. (2011). El derecho disciplinario en Colombia. "Estado del arte". Derecho Penal y Criminología, 32 (92): 115-154.

Gómez Pavajeau, C. A. (2012). El derecho disciplinario como disciplina jurídica autónoma. Revista Derecho Penal y Criminología, 23 (95), pp. 51-68.

Gómez-Valencia, H. (2006). Autoridad y control social en los pueblos indígenas andinos de Colombia. Ra Ximhai.Revista de Sociedad, Cultura y Desarrollo Sustentable, 2 (3): 683-715.

Herrera Echeverri, W. (2004). Teoría del delito. Manual. Medellín: Editora jurídica de Colombia.

Jiménez de Asúa, L. (1995). Lecciones de derecho penal. México: Editorial Pedagógica Iberoamericana.

Madrid-Malo Garizabal, M. (1998). Constitución Política de Colombia comentada por la Comisión Colombiana de Juristas. Bogotá: La Comisión.

Maggiore, G. (2000). Derecho penal. Bogotá: Temis.

Mújica Rivas, M. L. (2005). La dimensión pedagógica del término disciplina en San Agustín. Revista Española de Pedagogía, 43 (231): 309-324.

Muñoz Conde, F. (2005). Teoría general del delito. Bogotá: Temis.

Nieto, A. (1970). Problemas capitales del derecho disciplinario. Revista de Administración Pública, (63): $39-84$

Quintero, B. (2002). Teoría general del proceso. Bogotá: Temis S.A.

Quintero Restrepo, L. D. (2011). Tipicidad en materia disciplinaria: Tipos Abiertos y Numerus Apertus. Diálogos de Derecho y Política, 7 (2): 1-16.

Reyes Echandía, A. (1967). La tipicidad penal Bogotá: Universidad Externado de Colombia.

Tejada Correa, J.A. (2016). Debido proceso y procedimiento disciplinario laboral. Opinión Jurídica, 15 (30): 227-248.

The British Library Board. (2017). Magna Carta 1215. Consultado en http://www.bl.uk/ learning/timeline/item95692.html

Trayter Jiménez, J. M. (1991). El régimen disciplinario de los funcionarios públicos (Tesis doctoral). Universidad de Barcelona, Barcelona. 
Úbeda Tarajano, F. E. (2007). Sanciones disciplinarias de derecho público: Las relaciones entre ilícitos administrativos y penales en el marco constitucional. Boletín del Ministerio de Justicia, 61 (2033): 985-1030
Zaffaroni, E. R. (2002) Derecho penal. Parte general. Buenos Aires: Ediar.

Velásquez, F. (2007). Manual de derecho penal. Parte general. Medellín: Comlibros. 
